\title{
SCIDOC
}

\author{
International Journal of Dentistry and Oral Science (IJDOS) \\ ISSN: $2377-8075$
}

\section{Surface Roughness and Erosion of Bulk-fill Restorative Materials after Exposure to Acidic Beverages and Brushing}

Research Article

Saijai Tanthanuch ${ }^{1}$, Boonlert Kukiattrakoon ${ }^{2 *}$, Kullaporn Keawjinda ${ }^{3}$, Thanawat Udomaksorn ${ }^{3}$, Sivakorn Kongsaeng ${ }^{3}$, Amonjarat Ittiariyawikul ${ }^{3}$, Arunroj Konon ${ }^{3}$

${ }^{1}$ Associate Professor, Department of Conservative Dentistry, Faculty of Dentistry, Prince of Songkla University, Hat Yai, Songkhla, Thailand.

${ }^{2}$ Professor, Department of Conservative Dentistry and Dental Materials Research Unit (second phase), Faculty of Dentistry, Prince of Songkla University, Hat Yai, Songkhla, Thailand.

${ }^{3}$ Department of Conservative Dentistry, Faculty of Dentistry, Prince of Songkla University, Hat Yai, Songkhla, Thailand.

\section{Abstract}

Objectives: To investigate the effects of acidic beverages regarding brushing on surface roughness and erosion of bulk-fill restorative materials.

Methods: Sixty-seven specimens of each bulk-fill resin composite and giomer were prepared. Baseline data of surface roughness and erosion were recorded using a profilometer and surface characteristics were examined using scanning electron microscopy (SEM). Three groups of discs $(\mathrm{n}=22)$ were alternately immersed in $300 \mathrm{~mL}$ of each beverage for $5 \mathrm{~s}$ and in $300 \mathrm{~mL}$ of artificial saliva for $5 \mathrm{~s}$ for 10 cycles. After immersion, specimens were divided into two subgroups, the brushing group with automatic toothbrush for $2 \mathrm{~s}$ with a force of $2 \mathrm{~N}$ and the non-brushing group. This process was repeated every 8 hours. Surface roughness and erosion was recorded again on day $7,14,21$, and 28 , and surface characteristics were examined on day 28 . The specimens were evaluated and data were analyzed by repeated analysis of variance (ANOVA), Tukey's honestly significant difference and t-test ( $\alpha$ $=0.05$ ).

Results: Coca-cola caused significantly greater roughness and erosion than other groups $(\mathrm{P}<0.05)$. Giomer had significantly greater roughness and erosion than the bulk-fill resin composite $(\mathrm{P}<0.05)$. Brushing groups caused a rougher surface than nonbrushing groups $(\mathrm{P}<0.05)$.

Conclusions: The effects of coca-cola and orange juice on the surface roughness and erosion of bulk fill restorative materials depended on the physical and chemical composition of the restorative materials, $\mathrm{pH}$ of the beverages and brushing.

Keywords: Acidic Beverage; Brushing; Erosion; Surface Roughness; Bulk-Fill Restorative Materials.

\section{Introduction}

Tooth-colored filling materials are widely used in esthetic restorative dentistry. There are several kinds of tooth-colored filling materials such as resin-based composite (RBC), resin modified glass ionomer cement, glass ionomer cement, and giomer. Resinbased composites are the most popular restorative materials for posterior teeth. Nowadays, RBCs have been developed in a resin matrix, filler and initiator [1]. Additionally, development of adhesive systems and the physical, mechanical and esthetic properties of RBCs have also been improved [2], and are trending in many amalgam-banned in many countries. Recently, RBC technology development was launched as so-called, "bulk-fill RBCs" [3].

Bulk-fill RBC materials have become more widely used in posterior teeth than other restorative materials. They have many advantages such as their easy filling techniques in a single increment, presenting with a lower polymerization shrinkage stress [4], having a deeper depth of cure of 4-5 $\mathrm{mm} \mathrm{[5],} \mathrm{and} \mathrm{having} \mathrm{higher}$ light transmission properties because of light scattering at the filler-matrix interface by either reducing the filler amount [6] or increasing the filler size [7]. Moreover, they reduce cuspal deflec-

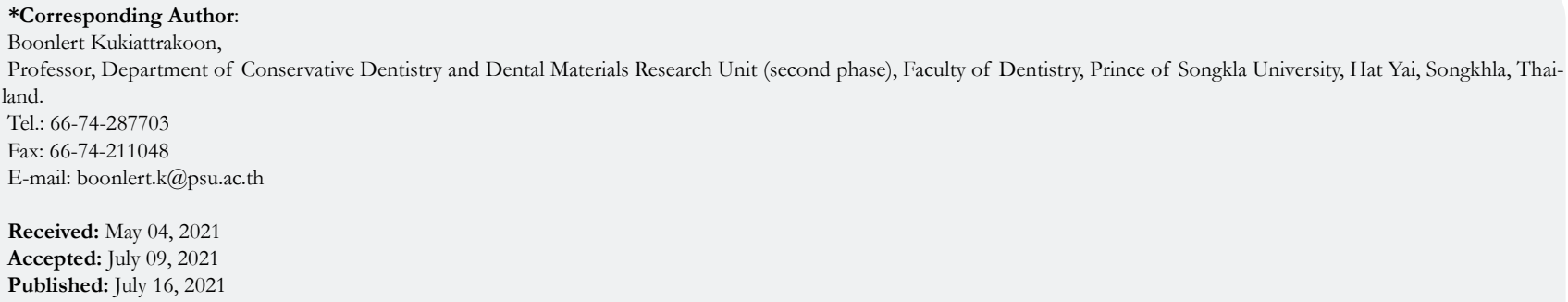

Citation: Saijai Tanthanuch, Boonlert Kukiattrakoon, Kullaporn Keawjinda, Thanawat Udomaksorn, Sivakorn Kongsaeng, Amonjarat Ittiariyawikul, et al., Surface Roughness and Erosion of Bulk-fill Restorative Materials after Exposure to Acidic Beverages and Brushing. Int J Dentistry Oral Sci. 2021;8(7):3188-3193. doi: http://dx.doi.org/10.19070/2377-807521000649

Copyright: Boonlert Kukiattrakoon ${ }^{\circ} 2021$. This is an open-access article distributed under the terms of the Creative Commons Attribution License, which permits unrestricted use, distribution and reproduction in any medium, provided the original author and source are credited. 
tion [8] and possess time-saving filling materials when compared with conventional resin composite filled by the multi-incremental layering technique $[3,4,6]$.

Giomers are the latest type of glass ionomer-composite hybrid esthetic restorative materials. They consist of a pre-reacted glass (PRG) filler and an organic-resin matrix [9]. They are polymerized with light-activated blue light with a wavelength of $470 \mathrm{~nm}$. The chemical compositions of giomers facilitates fluoride ion release and recharge so they can release and reuptake fluoride [10] with the potential for prevention of recurrent caries [11]. The giomers are easy to handle, have better polishability and are more esthetic than conventional glass ionomers [11].

The common reasons for RBC replacement are surface degradation, technique, fracture, and color alteration [12] because of the continuous exposure to saliva and acidic beverages/food within the oral conditions [13]. Degradation of RBCs might be related to the degree of the water sorption and the hydrophilic property of the resin matrix. Furthermore, the composition of the food-simulating liquid and beverages may degrade the surface of the restorative materials [13]. Moreover, tooth brushing also influences the restorative material's longevity. Abrasion may result in alterations of restorative material's surfaces affecting contour, coloration and favoring plaque retention caused by the surface roughness [12]. This raises the question whether acidic beverages and brushing could affect bulk-fill restorative materials or not. Therefore, the objectives of this in vitro study were to compare surface roughness and erosion of various bulk-fill restorative materials after exposure to acidic beverages and brushing, and to investigate the $\mathrm{pH}$ and titratable acidity of the different beverages. This study tested the hypothesis that the surface roughness and erosion of various bulk-fill restorative materials would not change after immersion in beverages and brushing.

\section{Materials and Methods}

\section{Specimen Preparations}

A total of 67 disc-shaped specimens $(10.0 \mathrm{~mm}$ in diameter and $2.0 \mathrm{~mm}$ in thickness) of each bulk-fill nanohybrid resin composite and giomer (shade A2, Table 1) were prepared in a polytetrafluoroethylene cylindrical mold on a glass slab and covered with a mylar matrix strip. A glass plate was then placed over the mylar strip. Excess materials extruded by applying a static load of approximately $200 \mathrm{~g}$, and a smooth and flat surface on each specimen was achieved. Consequently, the specimens were polymerized for $40 \mathrm{~s}$ with a light-activated polymerization unit (Elipar 2500, 3M ESPE, St. Paul, MN, USA). The light intensity was verified with a measuring device (Cure Rite, L.D. Caulk, Milford, DE, USA). After polymerization, the mylar strip and the glass plate on the top and the glass slab on the bottom of the mold were removed. The specimen was then removed from the cylindrical mold. Mechanical preparation or abrasions of the specimens were not performed.

\section{The $\mathrm{pH}$ and titratable acidity measurements}

Two acidic beverages, coca-cola and orange juice, were used in this study. Their compositions are shown in Table 2. The $\mathrm{pH}$ of each beverage was verified using a $\mathrm{pH}$ meter (Orion 900A, Orion
Research, Boston, MA, USA). Ten $\mathrm{pH}$ readings of each beverage were acquired in order to record a mean $\mathrm{pH}$ measurement.

Twenty $\mathrm{mL}$ of each beverage was added by $0.5 \mathrm{~mL}$ increments of $1 \mathrm{~mol} / \mathrm{L}$ sodium hydroxide $(\mathrm{NaOH})$ in order to measure titratable acidity (buffering capacity). The amount of $\mathrm{NaOH}$ required to reach $\mathrm{pH}$ levels of 5.5, 7.0 and 10.0 was recorded and repeated 10 times to obtain a mean value of the titrations for each storage agent.

\section{Acidic beverage immersions}

Sixty-seven discs of each bulk-fill nanohybrid resin composite and giomer were divided into three groups of 22 specimens for immersion in coca-cola, orange juice and deionized water (serving as the control). Each group was subjected to a surface roughness measurement and surface morphology analysis for baseline data (before immersion).

The specimens were then alternately immersed in $300 \mathrm{~mL}$ of an acidic beverage for $5 \mathrm{sec}$ and in $300 \mathrm{~mL}$ of artificial saliva for $5 \mathrm{sec}$ [14] conducted over 100 cycles at room temperature (about $25^{\circ} \mathrm{C}$ ). Consequently, the specimens were divided into 2 groups; brushing and non-brushing groups (control). For the brushing group, the specimens were brushed with an electric toothbrush (OralB Vitality Precision Clean, Procter \& Gamble, Cincinnati, $\mathrm{OH}$, USA) with $2 \mathrm{~N}$ force at $7,600 \mathrm{~Hz}$ for $2 \mathrm{sec}$ [15]. The specimens were cleaned in an ultrasonic bath (ELMA Transsonic 460/h Ultrasonic Bath, Elma GmbH \& Co KG, Singen, Germany) for 10 min to remove a smear layer [16]. This process was repeated every $8 \mathrm{hr}$ for simulating beverage consumption after 3 meals a day [17]. Alternated immersion of specimens in artificial saliva was incorporated as an attempt to simulate the washing effect in the oral cavity and through simulated brushing. The beverages were refreshed daily during the experiment to keep the original $\mathrm{pH}$ level of the beverages. Subsequently, the specimens were rinsed with deionized water, blotted dry against filter paper, and conducted to post experiment surface roughness and erosion measurement.

\section{Surface roughness and erosion measurements}

Surface roughness and erosion were measured by a profilometer (Surfcorder model SE-2300, Kosaka Laboratory Ltd., Tokyo, Japan). The cut-off value for surface roughness was $0.8 \mathrm{~mm}$ and the stylus navigating distance was $4 \mathrm{~mm}$. The radius of the stylus tip was $5 \mu \mathrm{m}$, and the stylus tip force and speed were $4 \mathrm{mN}$ and $0.5 \mathrm{~m} / \mathrm{s}$, respectively. The surface roughness values ( $\mathrm{Ra}$, the arithmetical average of surface heights) and erosion values (Rmax, the magnitude of the peak-to-valley height in all cutoff lengths) [18] of each specimen were achieved in five different positions (1.5 $\mathrm{mm}$ apart), each before and after the experiment (day 7, 14, 21 , and 28).

\section{Surface micromorphology analysis}

The effect of each beverage and brushing on the surface micromorphology of the materials before and after the experiment (day 28) was determined using a scanning electron microscope (JSM5800, JEOL, Tokyo, Japan). Three specimens of each restorative material from each group were examined at day 28 .

\section{Statistical analysis}


The surface roughness and erosion values were conducted to repeated analysis of variance (ANOVA), Tukey's honestly significant difference (HSD) and the t-test for multiple comparisons (at $\alpha=0.05)$

\section{Results}

Table 3 showed the mean $\mathrm{pH}$ and standard deviations (SDs) and titratable acidity of beverages with $1 \mathrm{~mol} / \mathrm{L} \mathrm{NaOH}$. Coca-cola had less $\mathrm{pH}(2.35 \pm 0.2)$ and less titratable acidity $(2.82 \pm 0.08$ $\mathrm{mL})$ than orange juice $(\mathrm{pH} 3.42 \pm 0.06$ and $8.39 \pm 0.3 \mathrm{~mL}$, respectively). Table 4 and 5 presented the surface roughness and erosion values of the materials used before and after the experiment. Generally, coca-cola caused significantly rougher surfaces than did orange juice and deionized water $(\mathrm{P}<0.05)$. Bulk-fill giomer were significantly rougher than bulk-fill nanohybrid RBCs after the experiments $(\mathrm{P}<0.05)$. Brushing groups caused rougher surfaces than non-brushing groups $(\mathrm{P}<0.05)$.

SEM photomicrographs of the bulk-fill nanohybrid resin composite and giomer before and after the 28-day experiment period in the different beverages are presented in Figures 1,2 and 3, respectively. Overall, the coca-cola groups produced the roughest specimen surface (figures $3 \mathrm{~A}$ and $3 \mathrm{~B}$ ). The brushing groups pre- sented rougher specimen surfaces than the non-brushing groups.

\section{Discussion}

The null hypothesis of this study was that surface roughness and erosion of various bulk-fill restorative materials would not change after immersion in beverages and brushing. On the basis of the data, the null hypothesis of this present study should be rejected. This study showed that after the first, second, third, and forth week of the experiment in all beverages, the surface roughness of the bulk-fill giomer significantly changed $(\mathrm{P}<0.05)$ in the brushing and non-brushing groups.

In this study, the mean surface roughness value and erosion of the specimens increased due to a chemical reaction or dissolution from the beverages as seen from SEM photomicrographs. The combination of quantitative assessment and qualitative evaluation by SEM supported qualitative data in three dimensions of the surface examined [19]. Roughness evaluations were obtained from 5 scans, spaced $1.5 \mathrm{~mm}$ apart, and each tracing a $4 \mathrm{~mm}$ distance to ensure the results were representative of the entire surface. Therefore, many measuring scans were required when using the profilometer.

Surface degradation of the restorative materials was associated

Table 1. Bulk-fill resin composite and giomer used in this study.

\begin{tabular}{|c|c|c|c|c|c|c|}
\hline Material & Type & Manufacturer & Resin & Filler & $\begin{array}{c}\text { Filler } \\
\text { size }(\mu \mathrm{m})\end{array}$ & $\begin{array}{c}\text { Filler } \\
\text { Volume } \\
(\%)\end{array}$ \\
\hline $\begin{array}{l}\text { Sonic- } \\
\text { Fill } 2\end{array}$ & $\begin{array}{l}\text { nano } \\
\text { hybrid }\end{array}$ & $\begin{array}{l}\text { Kerr, Orange, } \\
\text { CA, USA }\end{array}$ & $\begin{array}{l}\text { 3-trimethoxysilylpropyl methacry- } \\
\text { late, Bis-EMA, bisphenol-A-bis- } \\
\text { (2-hydroxy- 3-methacryloxypro- } \\
\text { pyl) ether, TEGDMA }\end{array}$ & $\begin{array}{l}\text { silicon dioxide, } \\
\text { barium glass }\end{array}$ & 0.4 & $83.50 \%$ \\
\hline \multirow{2}{*}{$\begin{array}{l}\text { BEAUTI- } \\
\text { FIL-Bulk } \\
\text { Restor- } \\
\text { ative }\end{array}$} & \multirow{2}{*}{ giomer } & $\begin{array}{c}\text { Shofu Dental } \\
\text { corp., }\end{array}$ & \multirow{2}{*}{$\begin{array}{l}\text { Bis-GMA, UDMA, Bis-MPEPP, } \\
\text { TEGDMA, DL-camphorquinone, } \\
\text { pigments and others }\end{array}$} & \multirow{2}{*}{$\begin{array}{l}\text { S-PRG filler based } \\
\text { on fluoroboro } \\
\text { alumino- silicate } \\
\text { glass }\end{array}$} & \multirow{2}{*}{0.8} & \multirow{2}{*}{$74.50 \%$} \\
\hline & & $\begin{array}{c}\text { San Marcos, } \\
\text { CA, USA }\end{array}$ & & & & \\
\hline
\end{tabular}

Bis-EMA: Ethoxylatedbisphenol-A dimethacrylate, TEGDMA: Triethyleneglycol dimethacrylate, Bis-GMA: Bisphenol-A glycidyl methacrylate, UDMA: Urethane dimethacrylate, Bis-MPEPP: Bisphenol A polyethoxymethacrylate, S-PRG: Surface pre-reacted glass-ionomer.

Table 2. Acidic beverages used in this study.

\begin{tabular}{|c|c|c|c|}
\hline Beverage & Trade name & Manufacturer & Composition \\
\hline Soft drink & Coca-cola & $\begin{array}{c}\text { Coca-Cola Com- } \\
\text { pany, Atlanta, GA, } \\
\text { USA }\end{array}$ & $\begin{array}{c}\text { carbonated water, sugar, caffeine, } \\
\text { phosphoric acid, caramel color, natural } \\
\text { flavorings }\end{array}$ \\
\hline $\begin{array}{c}\text { Orange } \\
\text { juice }\end{array}$ & $\begin{array}{c}100 \% \text { tangerine } \\
\text { orange juice }\end{array}$ & $\begin{array}{c}\text { Tipco F\&B, Bang- } \\
\text { kok, Thailand }\end{array}$ & $\begin{array}{c}\text { Tangerine orange, vitamin A, vitamin } \\
\text { C }\end{array}$ \\
\hline
\end{tabular}

Table 3. The mean $\mathrm{pH}$ and standard deviation and titratable acidity (volume of $\mathrm{NaOH}(\mathrm{mL})$ to bring $\mathrm{pH}$ to $5.5,7.0$ and 10.0$)$ of acidic beverages tested.

\begin{tabular}{|c|c|c|c|c|}
\hline \multirow{2}{*}{ Beverage } & \multirow{2}{*}{ Mean $\mathbf{p H} \pm \mathbf{S D}$} & \multicolumn{3}{|c|}{$\begin{array}{c}\text { Cumulative volume of } \mathbf{N a O H} \text { used } \\
\text { to titrate to each } \mathbf{p H}(\mathbf{m L})\end{array}$} \\
\cline { 3 - 5 } & & $\mathbf{5 . 5}$ & $\mathbf{7}$ & $\mathbf{1 0}$ \\
\hline Coca-cola & $2.35 \pm 0.2$ & $0.77 \pm 0.13$ & $1.57 \pm 0.03$ & $2.82 \pm 0.08$ \\
\hline Orange juice & $3.42 \pm 0.06$ & $4.9 \pm 0.15$ & $6.57 \pm 0.19$ & $8.39 \pm 0.3$ \\
\hline
\end{tabular}


Table 4. The mean surface roughness (Ra) values and standard deviations (SD) of bulk-fill restorative materials after experiments at different times.

\begin{tabular}{|c|c|c|c|c|c|c|c|}
\hline \multirow{3}{*}{ Material } & \multirow{3}{*}{$\begin{array}{l}\text { Storage } \\
\text { agent }\end{array}$} & \multirow{3}{*}{$\begin{array}{c}\text { Brushing / } \\
\text { non-brushing }\end{array}$} & \multicolumn{5}{|c|}{ Mean surface roughness $(\mu \mathrm{m}) \pm$ SD } \\
\hline & & & \multirow{2}{*}{$\begin{array}{c}\text { Before ex- } \\
\text { periment }\end{array}$} & \multicolumn{4}{|c|}{ After experiment } \\
\hline & & & & First week & Second week & Third week & Forth week \\
\hline \multirow{6}{*}{ SonicFill 2} & \multirow{2}{*}{$\begin{array}{c}\text { Deionized } \\
\text { water }\end{array}$} & & $0.02 \pm 0.01$ & $0.02 \pm 0.01 \mathrm{c}, \mathrm{G}$ & $0.02 \pm 0.01 c, G$ & $0.02 \pm 0.02 \mathrm{c}, \mathrm{G}$ & $0.02 \pm 0.01 \mathrm{c}, \mathrm{G}$ \\
\hline & & Non-brushi & $0.01 \pm 0.01$ & $0.02 \pm 0.01 \mathrm{c}, \mathrm{G}$ & $0.02 \pm 0.02 \mathrm{c}, \mathrm{G}$ & $0.02 \pm$ & $\mathrm{c}, \mathrm{G}$ \\
\hline & \multirow{2}{*}{ Coca-cola } & Brushing & $0.01 \pm 0.01$ & $0.13 \pm 0.02^{*}, \mathrm{a}, \mathrm{G}$ & $0.16 \pm 0.01 *, \mathrm{a}, \mathrm{E}$ & $0.20 \pm 0.02 *, \mathrm{a}, \mathrm{E}$ & $0.24 \pm 0.02 *, a, E$ \\
\hline & & Non-brushing & $0.02 \pm 0.01$ & $0.02 \pm 0.01 \mathrm{c}, \mathrm{G}$ & $0.02 \pm 0.01 \mathrm{c}, \mathrm{G}$ & $0.03 \pm 0.01 \mathrm{c}, \mathrm{G}$ & $0.03 \pm 0.02 \mathrm{c}, \mathrm{G}$ \\
\hline & \multirow{2}{*}{$\begin{array}{l}\text { Orange } \\
\text { juice }\end{array}$} & rushing & $0.01 \pm 0.01$ & $0.09 \pm 0.04 *, \mathrm{~b}, \mathrm{~F}$ & $0.12 \pm 0.03 *, \mathrm{~b}, \mathrm{~F}$ & $0.15 \pm 0.02 *, \mathrm{~b}, \mathrm{~F}$ & $0.19 \pm 0.02^{*}, \mathrm{~b}, \mathrm{~F}$ \\
\hline & & Non-brushing & $0.02 \pm 0.01$ & $0.02 \pm 0.01 \mathrm{c}, \mathrm{G}$ & $0.02 \pm 0.01 \mathrm{c}, \mathrm{G}$ & $0.03 \pm 0.02 \mathrm{c}, \mathrm{G}$ & $0.03 \pm 0.02 \mathrm{c}, \mathrm{G}$ \\
\hline \multirow{6}{*}{$\begin{array}{l}\text { BEAUTI- } \\
\text { FIL-Bulk } \\
\text { Restorative }\end{array}$} & \multirow{2}{*}{$\begin{array}{c}\text { Deionized } \\
\text { water }\end{array}$} & Brushing & $0.02 \pm 0.01$ & $0.02 \pm 0.01 \mathrm{e}, \mathrm{G}$ & $0.02 \pm 0.01 e, G$ & $0.02 \pm 0.01 \mathrm{e}, \mathrm{G}$ & $0.02 \pm 0.02 \mathrm{e}, \mathrm{G}$ \\
\hline & & Non-br & $0.01 \pm 0.01$ & $0.02 \pm 0.01 \mathrm{e}, \mathrm{G}$ & $0.02 \pm 0.01 \mathrm{e}, \mathrm{G}$ & $0.02 \pm 0.02 \mathrm{e}, \mathrm{G}$ & $0.02 \pm 0.01 \mathrm{e}, \mathrm{G}$ \\
\hline & \multirow{2}{*}{ Coca-cola } & & $0.02 \pm 0.01$ & $0.31 \pm 0.02 *, \mathrm{a}, \mathrm{A}$ & $0.39 \pm 0.01 *, \mathrm{a}, \mathrm{A}$ & $0.51 \pm 0.02 *, \mathrm{a}, \mathrm{A}$ & $0.72 \pm 0.03 *, \mathrm{a}, \mathrm{A}$ \\
\hline & & Non-brushing & $0.01 \pm 0.01$ & $0.22 \pm 0.02 *, \mathrm{c}, \mathrm{C}$ & $0.28 \pm 0.01 *, \mathrm{c}, \mathrm{C}$ & $0.32 \pm 0.02 *, \mathrm{c}, \mathrm{C}$ & $0.38 \pm 0.01 *, \mathrm{c}, \mathrm{C}$ \\
\hline & \multirow{2}{*}{$\begin{array}{l}\text { Orange } \\
\text { juice }\end{array}$} & Brushing & $0.01 \pm 0.01$ & $0.26 \pm 0.02 *, \mathrm{~b}, \mathrm{~B}$ & $0.32 \pm 0.02 *, \mathrm{~b}, \mathrm{~B}$ & $0.36 \pm 0.01 *, \mathrm{~b}, \mathrm{~B}$ & $0.43 \pm 0.02 *, \mathrm{~b}, \mathrm{~B}$ \\
\hline & & Non-brushing & $0.02 \pm 0.01$ & $0.18 \pm 0.01 *, \mathrm{~d}, \mathrm{D}$ & $0.23 \pm 0.02 *, \mathrm{~d}, \mathrm{D}$ & $0.28 \pm 0.02 *, \mathrm{~d}, \mathrm{D}$ & $0.32 \pm 0.02 *, \mathrm{~d}, \mathrm{D}$ \\
\hline
\end{tabular}

* indicates statistically significant difference (in rows) from the before experiment value according to the t- test $(\mathrm{P}<0.05)$.

a-d indicates statistically significant difference (in columns) among experiments (in column) for each material according to Tukey's HSD test (P $<$ $0.05)$.

A-G indicates statistically significant difference (in columns) among experiments and materials (in column) according to Tukey's HSD test (P $<$ $0.05)$.

Table 5. The mean erosion (Rmax) values and standard deviations (SD) of bulk-fill restorative materials after experiments at different times.

\begin{tabular}{|c|c|c|c|c|c|c|c|}
\hline \multirow{3}{*}{ Material } & \multirow{3}{*}{$\begin{array}{l}\text { Storage } \\
\text { agent }\end{array}$} & \multirow{3}{*}{$\begin{array}{c}\text { Brushing / } \\
\text { non-brushing }\end{array}$} & \multicolumn{5}{|c|}{ Mean erosion $(\mu \mathrm{m}) \pm \mathrm{SD}$} \\
\hline & & & \multirow{2}{*}{$\begin{array}{l}\text { Before ex- } \\
\text { periment }\end{array}$} & \multicolumn{4}{|c|}{ After experiment } \\
\hline & & & & First week & Second week & Third week & Forth week \\
\hline \multirow{6}{*}{$\begin{array}{c}\text { Sonic- } \\
\text { Fill } 2\end{array}$} & \multirow{2}{*}{$\begin{array}{c}\text { Deionized } \\
\text { water }\end{array}$} & & $5.25 \pm 0.05$ & $5.25 \pm 0.06 c, G$ & $5.26 \pm 0.04 c, G$ & $5.26 \pm 0.05 c, G$ & $5.27 \pm 0.06 \mathrm{c}, \mathrm{G}$ \\
\hline & & Non-brushing & $5.26 \pm 0.05$ & $5.26 \pm 0.06 c, G$ & $5.26 \pm 0.05 c, G$ & $5.27 \pm 0.04 c, G$ & $5.27 \pm 0.06 \mathrm{c}, \mathrm{G}$ \\
\hline & \multirow{2}{*}{ Coca-cola } & & $5.26 \pm 0.04$ & $6.13 \pm 0.05^{*}, \mathrm{a}, \mathrm{G}$ & $6.91 \pm 0.05^{*}, \mathrm{a}, \mathrm{E}$ & $7.35 \pm 0.04^{*}, \mathrm{a}, \mathrm{E}$ & $7.97 \pm 0.05^{*}, \mathrm{a}, \mathrm{E}$ \\
\hline & & Non-brushir & $5.27 \pm 0.05$ & $5.27 \pm 0.07 \mathrm{c}, \mathrm{G}$ & $5.27 \pm 0.06 c, G$ & $5.28 \pm 0.04 c, G$ & $5.28 \pm 0.05 c, G$ \\
\hline & \multirow{2}{*}{$\begin{array}{l}\text { Orange } \\
\text { juice }\end{array}$} & Brushing & $5.26 \pm 0.03$ & $5.91 \pm 0.04^{*}, \mathrm{~b}, \mathrm{~F}$ & $6.55 \pm 0.05^{*}, \mathrm{~b}, \mathrm{~F}$ & $7.22 \pm 0.06^{*}, \mathrm{~b}, \mathrm{~F}$ & $8.30 \pm 0.05^{*}, \mathrm{~b}, \mathrm{~F}$ \\
\hline & & Non-brushing & $5.27 \pm 0.04$ & $5.27 \pm 0.06 c, G$ & $5.27 \pm 0.06 c, G$ & $5.28 \pm 0.07 c, G$ & $5.28 \pm 0.07 c, G$ \\
\hline \multirow{6}{*}{$\begin{array}{c}\text { BEAUTI- } \\
\text { FIL-Bulk } \\
\text { Restor- } \\
\text { ative }\end{array}$} & \multirow{2}{*}{$\begin{array}{c}\text { Deionized } \\
\text { water }\end{array}$} & Brushing & $5.27 \pm 0.06$ & $5.27 \pm 0.04 \mathrm{e}, \mathrm{G}$ & $5.27 \pm 0.06 \mathrm{e}, \mathrm{G}$ & $5.28 \pm 0.06 \mathrm{e}, \mathrm{G}$ & $5.28 \pm 0.07 \mathrm{e}, \mathrm{G}$ \\
\hline & & Non-brushing & $5.27 \pm 0.04$ & $5.27 \pm 0.06 \mathrm{e}, \mathrm{G}$ & $5.27 \pm 0.07 \mathrm{e}, \mathrm{G}$ & $5.28 \pm 0.04 \mathrm{e}, \mathrm{G}$ & $5.28 \pm 0.04 \mathrm{e}, \mathrm{G}$ \\
\hline & \multirow{2}{*}{ Coca-cola } & Brushing & $5.26 \pm 0.07$ & $9.13 \pm 0.05^{*}, \mathrm{a}, \mathrm{A}$ & $13.32 \pm 0.06^{*}, \mathrm{a}, \mathrm{A}$ & $17.91 \pm 0.05^{*}, \mathrm{a}, \mathrm{A}$ & $22.12 \pm 0.06^{*}, \mathrm{a}, \mathrm{A}$ \\
\hline & & Non-brushing & $5.27 \pm 0.04$ & $7.58 \pm 0.03^{*}, \mathrm{c}, \mathrm{C}$ & $9.89 \pm 0.05^{*}, \mathrm{c}, \mathrm{C}$ & $13.42 \pm 0.04^{*}, \mathrm{c}, \mathrm{C}$ & $17.18 \pm 0.03^{*}, \mathrm{c}, \mathrm{C}$ \\
\hline & \multirow{2}{*}{$\begin{array}{l}\text { Orange } \\
\text { juice }\end{array}$} & Brushing & $5.27 \pm 0.05$ & $8.16 \pm 0.05^{*}, \mathrm{~b}, \mathrm{~B}$ & $11.25 \pm 0.05^{*}, \mathrm{~b}, \mathrm{~B}$ & $15.11 \pm 0.05^{*}, \mathrm{~b}, \mathrm{~B}$ & $19.02 \pm 0.03^{*}, \mathrm{~b}, \mathrm{~B}$ \\
\hline & & Non-brushing & $5.26 \pm 0.04$ & $6.27 \pm 0.04 *, \mathrm{~d}, \mathrm{D}$ & $8.42 \pm 0.04 *, \mathrm{~d}, \mathrm{D}$ & $11.85 \pm 0.05^{*}, \mathrm{~d}, \mathrm{D}$ & $14.53 \pm 0.06^{*}, \mathrm{~d}, \mathrm{D}$ \\
\hline
\end{tabular}

* indicates statistically significant difference (in rows) from the before experiment value according to the t- test $(\mathrm{P}<0.05)$

a-d indicates statistically significant difference (in columns) among experiments (in column) for each material according to Tukey's HSD test (P $<$ $0.05)$.

A-G indicates statistically significant difference (in columns) among experiments and materials (in column) according to Tukey's HSD test (P < $0.05)$.

Figure 1: SEM photomicrographs of before immersion $(\times 300)$. (A) bulk-fill resin composite (SonicFill 2); (B) bulk-fill giomer (BEAUTIFIL-Bulk Restorative).

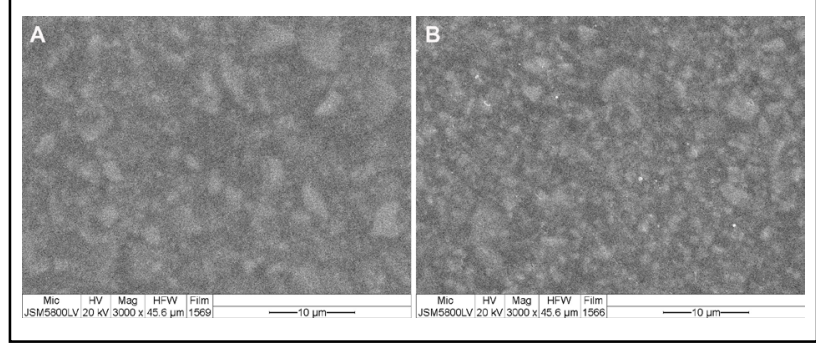


Figure 2. SEM photomicrographs of SonicFill 2 resin composite $(\times 300)$. (A) deionized water and brushing; $(\mathrm{B})$ deionized water and non-brushing; (C) coca-cola and brushing; (D) coca-cola and non-brushing; (E) orange juice and brushing; and (F) orange juice and non-brushing.

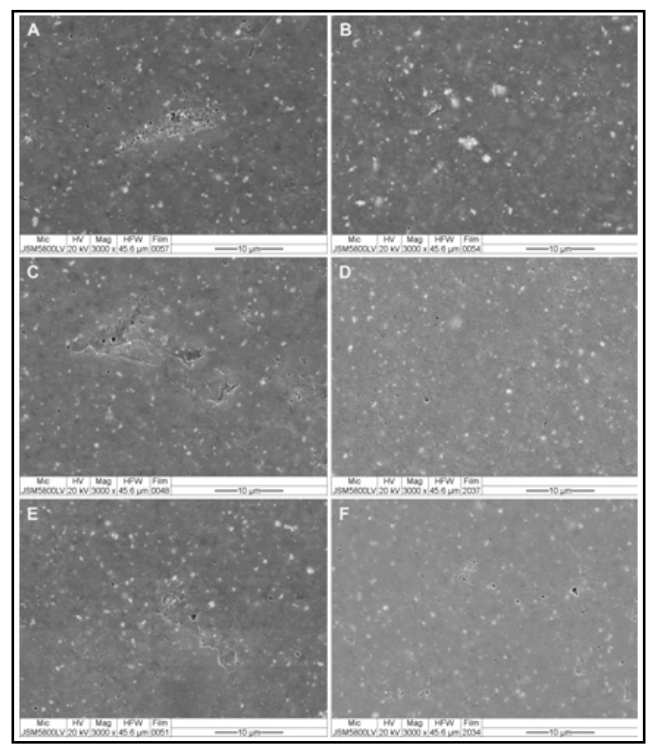

Figure 3. SEM photomicrographs of BEAUTIFIL-Bulk Restorative $(\times 300)$. (A) deionized water and brushing; (B) deionized water and non-brushing; (C) coca-cola and brushing; (D) coca-cola and non-brushing; (E) orange juice and brushing; and $(F)$ orange juice and non-brushing.

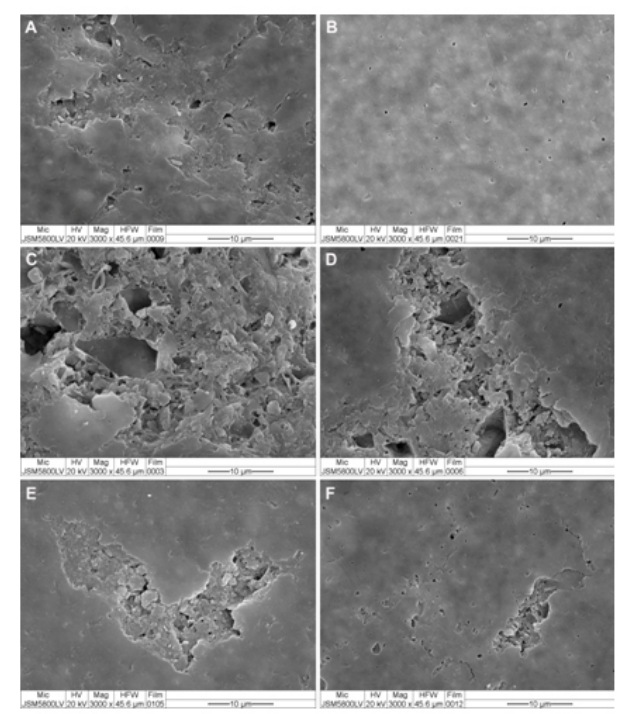

with the $\mathrm{pH}$ and the titratable acidity, which corresponds to previous studies $[13,14,17,20,21]$. Moreover, many studies have shown that acids might change the physical properties of RBCs and giomer under acidic conditions over time [13, 14, 17, 20, 21] which correlated to the results of this study where the beverage acidity had a $\mathrm{pH}$ ranging between 2.35 and 3.42. Coca-cola is a popular soft drink having the lowest $\mathrm{pH}$ of the beverages in the present study. After immersing the specimens in the beverages, coca-cola produced the roughest surfaces. It has been reported that a low $\mathrm{pH}$ in acidic food and drink induces erosive wear in materials $[13,14,17,20,21]$. The erosive potential of an acid beverage is not only exclusively influenced by its $\mathrm{pH}$, but also strongly depends on its tritratable acid content [20]. The $\mathrm{pH}$ values indicate only a measure of the free hydrogen ion concentration. It does not take into account the existing hydrogen ions remaining in undissociated forms. Thus, the potential surface degradation of RBCs and giomers from acidic beverages should be measured for both the $\mathrm{pH}$ value and titratable acidity $[13,20]$. Some drinks appear to be less erosive than others within the same $\mathrm{pH}$. It may also be possibly related to the type of acid used in the drinks' preparations. Orange juice is composed of citric acid while cocacola is a carbonated beverage containing carbonic acid and phosphoric acid which promotes dissolution and easily eroded the materials $[13,20]$. Phosphoric acid softens materials more than citric acid and carbonic acid. However, citric acid has been shown to be aggressive for dental hard tissues and resin based restorative materials $[13,20]$. Acidity might affect increases in dissolving, soften the polymer matrixes and dislodge the filler particles resulting in reducing the load resistance and increasing surface roughness and the degree of erosion in RBCs and giomer [13, 14, 17, 20, 21]. In comparison to giomers, RBCs were found to be less affected by low $\mathrm{pH}$ beverages or acid solution [20]. Therefore, SonicFill 2 resin composite exhibited less change in surface hardness values than Beautifil bulk giomer.

Moreover, the effect of water absorption might degrade polymer materials [22]. When polymer materials absorb water, coupling agents cause hydrolysis and loss of chemical bond between resin 
matrix filler and particles. Filler particles also dislodge from the outer surface of the material resulting in rapid increase in surface roughness, reduction of surface microhardness of RBCs and giomer, and facilitate the erosion of RBCs and giomer causing surface roughness and erosion of RBCs and giomer [23].

The filler size has been related with the surface characteristics of RBCs. The results of this study showed that BEAUTIFIL-Bulk Restorative (giomer) presented greater surface roughness than SonicFill 2 after soaking in acidic beverages, corresponding with SEM photomicrographs. Large filler particles will have rougher surfaces than smaller filler particles. The RBCs used in this study were SonicFill 2 (nanohybrid RBCs), which has an average filler particle size of $0.4 \mu \mathrm{m}$ and a smaller particle size than that of the BEAUTIFIL-Bulk Restorative (giomer), which has an average filler particle size of $0.8 \mu \mathrm{m}$.

The simulated brushing could have favored some changes in the restorative material surface. This present in vitro study simulated brushing to be a factor to measure the restorative material's ability to maintain the smoothness, brightness, and avoid staining [24]. The greater the number of brushing cycles and periods, the greater the degradation of the RBCs with higher surface roughness [24]. Likewise, in this present study, simulated brushing significantly increased of surface roughness as a result of the gradual removal of the filler particles during the brushing procedure. This would explain the difference observed by this present study, in which BEAUTIFIL-Bulk Restorative had rougher surfaces than SonicFill 2, in agreement with other studies [12].

The results of this study showed that acidic beverages and brushing may affect the surface roughness and erosion of bulk-fill restorative materials. However, this study only evaluated the in vitro effects, with some limitations. The dilution effects of saliva, including the $\mathrm{pH}$ change in the oral cavity, should also be considered. Therefore, further studies are required to examine the effects of acidic beverages in vivo. This study at least confirms the erosive potential of acidic beverages with brushing and how they can potentially degrade bulk-fill restorative materials. The public should be concerned about this fact.

\section{Conclusion}

Within the limitations of this study, the following conclusions could be drawn. Coca-cola significantly caused rougher surfaces and erosion than orange juice. Coca-cola and orange juice significantly increased surface roughness and erosion of giomer, compared with bulk-fill RBCs. Brushing groups caused rougher surfaces than non-brushing groups.

\section{Acknowledgements}

This study was supported by Faculty of Dentistry research fund and Prince of Songkla University.

\section{References}

[1]. Leprince JG, Palin WM, Hadis MA, Devaux J, Leloup G. Progress in dimethacrylate-based dental composite technology and curing efficiency. Dent Mater. 2013 Feb;29(2):139-56. Pubmed PMID: 23199807.

[2]. Beun S, Glorieux T, Devaux J, Vreven J, Leloup G. Characterization of nanofilled compared to universal and microfilled composites. Dent Mater.
2007 Jan;23(1):51-9. Pubmed PMID: 16423384.

[3]. Ilie N, Bucuta S, Draenert M. Bulk-fill resin-based composites: an in vitro assessment of their mechanical performance. Oper Dent. 2013 NovDec;38(6):618-25. Pubmed PMID: 23570302.

[4]. Marovic D, Tauböck TT, Attin T, Panduric V, Tarle Z. Monomer conversion and shrinkage force kinetics of low-viscosity bulk-fill resin composites. Acta Odontol Scand. 2015 Aug;73(6):474-80. Pubmed PMID: 25543454.

[5]. Leprince JG, Palin WM, Hadis MA, Devaux J, Leloup G. Progress in dimethacrylate-based dental composite technology and curing efficiency. Dent Mater. 2013 Feb;29(2):139-56. Pubmed PMID: 23199807.

[6]. Moorthy A, Hogg CH, Dowling AH, Grufferty BF, Benetti AR, Fleming GJ. Cuspal deflection and microleakage in premolar teeth restored with bulk-fill flowable resin-based composite base materials. J Dent. 2012 Jun;40(6):5005. Pubmed PMID: 22390980.

[7]. Amirouche-Korichi A, Mouzali M, Watts DC. Effects of monomer ratios and highly radiopaque fillers on degree of conversion and shrinkage-strain of dental resin composites. Dent Mater. 2009 Nov;25(11):1411-8. Pubmed PMID: 19683808.

[8]. Ilie N, Stark K. Curing behaviour of high-viscosity bulk-fill composites. J Dent. 2014 Aug;42(8):977-85. Pubmed PMID: 24887360.

[9]. Gordan VV, Mondragon E, Watson RE, Garvan C, Mjör IA. A clinical evaluation of a self-etching primer and a giomer restorative material: results at eight years. J Am Dent Assoc. 2007 May;138(5):621-7. Pubmed PMID: 17473040.

[10]. Naoum S, Ellakwa A, Martin F, Swain M. Fluoride release, recharge and mechanical property stability of various fluoride-containing resin composites. Oper Dent. 2011 Jul-Aug;36(4):422-32. Pubmed PMID: 21819201.

[11]. Yap AU, Mok BY. Surface finish of a new hybrid aesthetic restorative material. Oper Dent. 2002 Mar-Apr;27(2):161-6. Pubmed PMID: 11933907.

[12]. Mara da Silva T, Barbosa Dantas DC, Franco TT, Franco LT, Rocha Lima Huhtala MF. Surface degradation of composite resins under staining and brushing challenges. J Dent Sci. 2019 Mar;14(1):87-92. Pubmed PMID: 30988884.

[13]. Tanthanuch S, Kukiattrakoon B, Eiam-O-Pas K, Pokawattana K, Pamanee $\mathrm{N}$, Thongkamkaew W, et al. Surface changes of various bulk-fill resin-based composites after exposure to different food-simulating liquid and beverages. J Esthet Restor Dent. 2018 Mar;30(2):126-135. Pubmed PMID: 29171163.

[14]. Wongkhantee S, Patanapiradej V, Maneenut C, Tantbirojn D. Effect of acidic food and drinks on surface hardness of enamel, dentine, and toothcoloured filling materials. J Dent. 2006 Mar;34(3):214-20. Pubmed PMID: 16087287.

[15]. Fujimoto Y, Iwasa M, Murayama R, Miyazaki M, Nagafuji A, Nakatsuka T. Detection of ions released from S-PRG fillers and their modulation effect. Dent Mater J. 2010 Aug;29(4):392-7. Pubmed PMID: 20610878.

[16]. Lefever D, Perakis N, Roig M, Krejci I, Ardu S. The effect of toothbrushing on surface gloss of resin composites. Am J Dent. 2012 Feb;25(1):54-8. Pubmed PMID: 22558694.

[17]. Tantanuch S, Kukiattrakoon B, Peerasukprasert T, Chanmanee N, Chaisomboonphun P, Rodklai A. Surface roughness and erosion of nanohybrid and nanofilled resin composites after immersion in red and white wine. J Conserv Dent. 2016 Jan-Feb;19(1):51-5. Pubmed PMID: 26957794.

[18]. Stout KJ. Surface roughness $\square$ measurement, interpretation and significance of data. Materials \& Design. 1981 Sep 1;2(5):260-5.

[19]. Whitehead SA, Shearer AC, Watts DC, Wilson NH. Comparison of two stylus methods for measuring surface texture. Dent Mater. 1999 Mar;15(2):7986. Pubmed PMID: 10551099.

[20]. Tanthanuch S, Kukiattrakoon B, Siriporananon C, Ornprasert N, Mettasitthikorn W, Likhitpreeda S, et al. The effect of different beverages on surface hardness of nanohybrid resin composite and giomer. J Conserv Dent. 2014 May;17(3):261-5. Pubmed PMID: 24944451.

[21]. Tanthanuch S, Kukiattrakoon B. Degradability of nanocomposites after cyclic immersion in red and white wines. Journal of Orofacial Sciences. 2016 Jan 1;8(1):40

[22]. Göpferich A. Mechanisms of polymer degradation and erosion. Biomaterials. 1996 Jan;17(2):103-14. Pubmed PMID: 8624387.

[23]. Santos C, Clarke RL, Braden M, Guitian F, Davy KW. Water absorption characteristics of dental composites incorporating hydroxyapatite filler. Biomaterials. 2002 Apr;23(8):1897-904. Pubmed PMID: 11950060.

[24]. Heintze SD, Forjanic M, Ohmiti K, Rousson V. Surface deterioration of dental materials after simulated toothbrushing in relation to brushing time and load. Dent Mater. 2010 Apr;26(4):306-19. Pubmed PMID: 20036418. 